\title{
FORMAR PARA INCLUIR, INCLUIR PARA FORMAR: PERSPECTIVAS PARA UMA EDUCAÇÃO INCLUSIVA
}

\section{FORMING TO INCLUDE, INCLUDING TO FORM: PERSPECTIVES FOR AN INCLUSIVE EDUCATION}

\author{
Lucia da Cruz de Almeida e Karla Silene Oliveira Marinho
}

Universidade Federal Fluminense

\begin{abstract}
Resumo
Este artigo tem como objetivo apresentar o relato de uma experiência voltada para a formação de futuros professores de Física comprometidos com a educação inclusiva. Para tanto, são apresentados, inicialmente, dispositivos legais e fundamentos teóricos que subsidiaram o desenvolvimento da experiência, bem como, os principais obstáculos e perspectivas para a inclusão de alunos com necessidades educacionais especiais na rede regular de ensino. Em seguida, além dos aspectos metodológicos adotados na experiência que culminaram com a opção por ações relativas ao ensino de Física para videntes e não-videntes, são apresentados os resultados alcançados em prol da formação de professores conscientes de que a ação docente é um dos pilares que permitirá a concretização da educação inclusiva no contexto escolar.
\end{abstract}

Palavras-chave: educação inclusiva - formação do professor - ensino de Física

\begin{abstract}
:
The purpose of this article is to present the account of an experience directed to the formation of future Physics teacher compromised with the inclusive education. For this, we presented, initially, legal devices and theoretical fundamentals that subsidized the development of the experience, as well as, the main obstacles and perspectives for the include students with special education necessities in the regular schools. After that, beyond to the methodological aspects adopted in the experience that culminated with the option for relative actions to the Physics education for the seers and non-seers, we present the results reached in favor of the formation of conscientious teachers of that the teaching action is one of them pillars that the concretion of the inclusive education in the school context.
\end{abstract}

Keywords: inclusive education - teacher formation - physics teaching

\section{Educação Nacional: bases legais da educação inclusiva}

Percebe-se que a legislação brasileira tem procurado avançar na perspectiva da educação inclusiva. Assim, sem a pretensão de apresentar uma análise documental, procurar-se-á destacar documentos e dados oficiais que demonstram os avanços, a fim 
de melhor delinear os obstáculos e as perspectivas para a inclusão de sujeitos com necessidades educacionais especiais (NEE) nas escolas da rede regular e, mais especificamente, nas aulas de Física das classes comuns do Ensino Médio.

De acordo com a Constituição da República Federativa do Brasil, a educação é um direito de todos, devendo permitir o pleno desenvolvimento da pessoa, tanto para o exercício da cidadania quanto para a continuidade dos estudos e qualificação para o trabalho (BRASIL, 1988). Subentende-se, então, que a educação é, também, um direito dos educandos com NEE.

Essa forma de interpretação é ratificada em diversos trechos do texto da LDBEN de 1996, dentre os quais se destacam os seguintes:

\footnotetext{
(...) ensino será ministrado com base nos seguintes princípios: igualdade de condições para o acesso e permanência na escola (...); o dever do Estado com educação escolar pública será efetivado mediante a garantia de: (...) atendimento educacional especializado gratuito aos educandos com necessidades especiais, preferencialmente na rede regular de ensino; (...) os sistemas de ensino assegurarão aos educandos com necessidades especiais professores com especialização adequada em nível médio ou superior, para atendimento especializado, bem como professores do ensino regular capacitados para a integração desses educandos nas classes comuns (BRASIL, 1996).
}

De maneira mais incisiva ou esclarecedora, o Conselho Nacional de Educação, através da Resolução CNE/CEB nº 2/2001, instituiu as Diretrizes Nacionais para a educação de alunos com NEE na Educação Básica, determinando, em seu Art. 2ª que:

\footnotetext{
Os sistemas de ensino devem matricular todos os alunos, cabendo às escolas organizarem-se para o atendimento aos educandos com necessidades educacionais especiais, assegurando as condições necessárias para uma educação de qualidade para todos (BRASIL, 2001).
}

Tradicionalmente a educação especial se organizou e atuou socialmente como atendimento educacional especializado substitutivo ao ensino comum, entretanto, no decorrer da última década, após diversos Decretos, Resoluções, entre outros documentos oficiais, a educação especial perdeu o caráter substitutivo, devendo, então, passar a integrar a proposta pedagógica da escola regular. Desse modo, de acordo com o documento que traça a atual Política Nacional de Educação Especial na Perspectiva da Educação Inclusiva, os sistemas de ensino deverão garantir a transversalidade da educação especial desde a Educação Infantil até a Educação Superior (BRASIL, s/da). 
O Ministério da Educação (s/db), a partir da análise dos Censos Escolares, verificou que o número de matrículas de alunos com NEE em escolas regulares/ classes comuns aumentou, atingindo cerca de $50 \%$ em 2008, como pode ser constatado no Gráfico 1 a seguir.

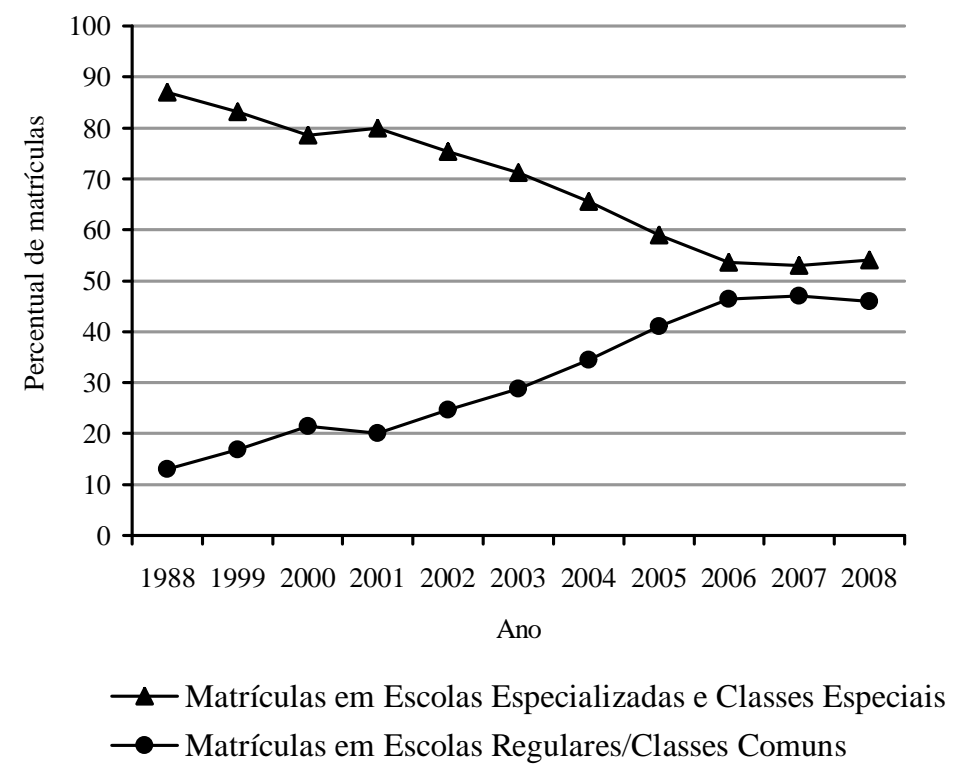

Gráfico 1: Evolução da política de inclusão nas classes comuns do ensino regular.

Considera-se, contudo, que esse aumento no número de matriculados no ensino regular não se caracteriza como garantia para que no cotidiano escolar esteja ocorrendo, de fato, a inclusão dos alunos com NEE, levando-se em conta que "estar junto é se aglomerar no cinema, no ônibus e até na sala de aula (...) inclusão é estar com, é interagir com o outro" (MANTOAN, 2005).

Nesse sentido, apesar de necessárias, percebe-se que as políticas educacionais não se configuram, ainda, como suficientes na proposição e implementação de projetos pedagógicos voltados para a inclusão dos alunos com NEE.

Se por um lado, a Escola, enquanto instituição social, não pode se omitir no enfrentamento das demandas decorrentes das mudanças sociais, por outro, a Universidade, responsável pela formação de futuros professores, não pode ficar alheia aos desafios que lhes serão apresentados na docência em classes comuns da Educação Básica. 
A falta de metas inclusivas, por parte da Escola e da Universidade, poderá resultar apenas no aumento do quantitativo de alunos com NEE matriculados na rede regular de ensino, ou seja, resultará na integração desses alunos. Todavia, Guijarro (2005) ressalta que os significados de integração e inclusão são diferentes.

A inclusão é um movimento mais amplo e de natureza diferente ao da integração de alunos com deficiência ou de outros alunos com necessidades educacionais especiais. Na integração, o foco de atenção tem sido transformar a educação especial para apoiar a integração de alunos com deficiência na escola comum. Na inclusão, porém, o centro da atenção é transformar a educação comum para eliminar as barreiras que limitam a aprendizagem e participação de numerosos alunos e alunas (p. 7).

Em linhas gerais, o conceito de inclusão social, segundo Veríssimo (2001) pode ser, assim, expresso:

Processo pelo qual a sociedade se adapta para poder incluir, em seus sistemas sociais gerais, pessoas com necessidades especiais e, simultaneamente, estas se preparam para assumir seus papéis na sociedade. Trata-se de um processo bilateral no qual as pessoas, ainda excluídas, e a sociedade buscam equacionar problemas, decidir sobre soluções e efetivar a equiparação de oportunidades para todos.

Esta conceituação implica em uma prática de inclusão social que tem por base os seguintes princípios: "aceitação das diferenças individuais; valorização de cada pessoa; a convivência dentro da diversidade humana; a aprendizagem através da cooperação" (Veríssimo, 2001).

No contexto escolar, a concretização desta prática está condicionada, dentre outros aspectos, a seguinte percepção:

(...) cada aluno tem uma capacidade, interesse, motivações e experiência pessoal única (...) a diversidade está dentro do 'normal' (...) a ênfase está em desenvolver uma educação que valorize e respeite às diferenças, vendo-as como uma oportunidade para otimizar o desenvolvimento pessoal e social e para enriquecer os processos de aprendizagem (Guijarro, 2005, p.10).

É inegável que essa concepção subentende mudanças nas práticas educativas, implicando uma maior competência profissional dos professores.

\section{A formação de professores na perspectiva da educação inclusiva}

Tal como Mantoan (2008), considera-se que a concretização da educação inclusiva pressupõe conceber a Escola como "um lugar privilegiado de encontro com o 
outro (...) que é sempre e necessariamente diferente" (p. 67). Contudo, para que essa concepção se fortaleça no contexto escolar, torna-se imprescindível o estabelecimento de "uma educação em que a heterogeneidade do grupo não é mais um problema, mas um grande desafio à criatividade e ao profissionalismo dos profissionais da educação, gerando e gerindo mudanças de mentalidades, de políticas e de práticas educativas" (SANCHES e TEODORO, 2007, p.110).

Assim, um dos obstáculos que se apresenta à educação inclusiva está relacionado com a formação de professores. Para Duk (2006),

\begin{abstract}
A maioria dos docentes formou-se e continua sendo formada com base em uma perspectiva tradicional homogeneizadora da ação docente que se centra na transmissão de conhecimentos teóricos e fragmentados entre si, os quais tendem a não apresentar relevância social tanto para a escola como para o estudante (...) a formação inicial e continuada de professore(a)s se caracteriza por uma relação pobre com os problemas e as situações enfrentadas pelos docentes nas suas práticas de sala de aula ou na vida escolar. Uma formação com tais características, portanto, não cria as bases para o desenvolvimento profissional contínuo dos docentes no que tange ao seu papel e função de educador e nem se articula com o aperfeiçoamento de práticas de ensino pedagogicamente mais efetivas e inclusivas (p.22).
\end{abstract}

Essa constatação é reafirmada por Pletsch (2009) ao apresentar resultados de diferentes pesquisas sobre o tema, concluindo que:

No Brasil, a formação de professores e demais agentes educacionais ligados à educação segue ainda um modelo tradicional, inadequado para suprir as reivindicações em favor da educação inclusiva. (...) O fato é que, de maneira geral, as licenciaturas não estão preparadas para desempenhar a função de formar professores que saibam lidar com a heterogeneidade posta pela inclusão (p. 150).

Sobre a formação inicial de professores com vistas às práticas de ensino inclusivas, Rodrigues (2008) considera que ao longo do curso e em cada disciplina deveriam ser contemplados conteúdos, aqui compreendidos como conhecimentos, procedimentos e valores, facilitadores a uma futura atuação profissional inclusiva (p.11). Todavia, este autor constata que o impedimento a esse modelo de formação reside no fato de que "nem todos os formadores sabem como lecionar nas suas áreas disciplinares estes conteúdos” (p.11).

O ideal, então, seria que os formadores assumissem a necessidade de ampliar seus conhecimentos em prol de planejamentos e ações didáticas, no âmbito das especificidades dos seus conteúdos, a fim de favorecer aos futuros professores o 
desenvolvimento de competências que os tornassem agentes de uma educação inclusiva, concebida como aquela que:

\footnotetext{
promove a heterogeneidade em lugar da homogeneidade, a construção de saberes em lugar da sua mera transmissão, a promoção do sucesso para todos em lugar da seleção dos academicamente mais aptos e a cooperação em lugar da competição (RODRIGUES, 2008, p.11).
}

Esse ideal deveria ser o eixo norteador das concepções curriculares e das práticas docentes nas Licenciaturas. Porém, como está condicionado a um processo que depende do coletivo de seus profissionais, tem se mostrado como difícil de ser alcançado em um curto espaço de tempo. Assim, do mesmo modo que SANCHES e TEODORO (2007) propõem que as ações educacionais inclusivas se iniciem com as condições que o contexto escolar oferece, "no intuito de gerar e bem gerir as condições necessárias" (p.114), considera-se que nas Licenciaturas sejam criados e/ou ocupados espaços pedagógicos que favoreçam a reflexão, a construção e a disseminação de conhecimentos que possam contribuir para mudanças de mentalidade, proposição e implementação de currículos que visem à formação de professores-educadores comprometidos com uma educação para todos.

\section{A formação do professor de Física: relato de uma experiência}

$\mathrm{Na}$ Universidade Federal Fluminense (UFF), a vasta literatura e dispositivos legais, dentre os quais se destacam a Portaria No 1793 (BRASIL, 1994), o Decreto N $^{\circ}$ 3298 (BRASIL, 1999) e o Decreto $\mathrm{N}^{\circ} 5626$ (BRASIL, 2005), não têm sido suficientemente explorados na elaboração das propostas curriculares e projetos políticopedagógicos das Licenciaturas.

No que diz respeito à Licenciatura em Física, constatou-se que a lacuna na proposta curricular tinha sua origem no "despreparo" dos docentes responsáveis pelas disciplinas obrigatórias que articulam os conhecimentos físicos com os didáticometodológicos, em prol da formação de professores para a Educação Básica aptos ao planejamento e implementação de propostas de ensino de Física alternativas às aulas exclusivamente expositivas (COSTA; MARINHO; ALMEIDA, 2008).

Esta constatação, ao invés de se configurar como obstáculo, foi assumida como um desafio a ser transposto. Para tanto, no início de 2007, mesmo sem as condições 
ideais e, balizado pela proposição de Sanches e Teodoro (2007, p.114) mencionada anteriormente, foi criado um Grupo de Estudos (GE) sobre educação inclusiva e ensino de Física, formado por três docentes do Departamento de Física e quatro licenciandos.

A primeira etapa das atividades do GE consistiu no levantamento, leitura e discussão de bibliografia pertinente à temática educação especial, a fim de permitir melhor compreensão de sua evolução histórica, particularmente no que se refere aos significados e diferenciações entre segregação, integração e inclusão. Essa etapa, compreendida como um processo de aprendizagem reflexiva teve sua continuidade com a análise de material bibliográfico relativo ao ensino de Física para alunos com NEE. Essa análise despertou no GE o interesse pelas questões concernentes às NEE visuais e pelas possibilidades de produzir recursos didáticos voltados para a inclusão de nãovidentes em aulas de Física nas classes comuns da rede regular.

Contudo, um trabalho de campo precedeu a etapa relativa à produção de recursos didáticos, tendo em vista a conscientização dos componentes do GE de que a elaboração de propostas de ensino para alunos com NEE deva ser necessariamente antecedida por estudo que leve em conta a percepção desses sujeitos acerca de suas vivências escolares e a de seus professores no processo de ensino, com o intuito de identificar barreiras existentes no contexto escolar e buscar alternativas que contribuam para removê-las (SOUZA, LEBEDEF e BARLETTE, 2007; SANTOS, 2000; COSTA, NEVES E BARONE, 2006).

Sendo assim, como segunda etapa de suas atividades, o GE decidiu pela realização de visitas a quatro escolas públicas da rede regular de ensino do Estado do Rio de Janeiro, localizadas em Niterói - município sede da UFF -, a fim de: coletar dados relativos ao número de deficientes visuais, comparativamente ao total de alunos das escolas; identificar os alunos portadores de NEE visuais; agendar e realizar entrevistas com esses alunos e seus professores; verificar as condições e a infraestrutura das escolas para o atendimento aos alunos na perspectiva da educação inclusiva.

Além das escolas selecionadas, o GE estreitou relações com a Associação Fluminense de Amparo aos Cegos, instituição localizada em Niterói, município sede da UFF, o que possibilitou maior familiarização com questões educacionais relativas aos deficientes visuais e a inclusão de mais uma escola, também da rede pública, a ser visitada no trabalho de campo. 
Para o trabalho de campo foram elaborados: um quadro para a coleta e organização dos dados quantitativos por escola e nível de ensino; um questionário semiestruturado visando à realização das entrevistas. O questionário contemplava questões relativas: ao nível da capacidade visual (visão subnormal ou baixa visão - leve, moderada, severa e profunda; ausência de visão - cegueira); ao fator (congênito ou ambiental) da capacidade visual; ao acesso à educação formal (escola regular; escola regular em classe especial; escola especial, etc); à convivência social com alunos e professores videntes; aos processos de ensino e de aprendizagem em Física (dificuldades, facilidades, críticas e sugestões).

Apesar dos Censos Escolares, destinados à coleta de dados sobre a Educação Básica nacional, contemplarem, desde 1999, nos questionários anuais, informações relativas à Educação Especial (BRASIL, s/dc), no que se refere às escolas visitadas, esses dados não se encontravam organizados para consulta ou, devido a outros fatores, não eram facilmente disponibilizados. Esta afirmação torna-se possível a partir dos obstáculos enfrentados pelo GE na obtenção dos dados, já que à exceção de uma escola, foi possível perceber: a falta de comprometimento das direções ou coordenações pedagógicas para indicar os responsáveis nas escolas pelo fornecimento de dados; o desinteresse em agendar encontro com componentes do GE; desconhecimento da existência de aluno(s) com NEE visuais matriculado(s) nas escolas (ALMEIDA et al., 2009).

Isto fez com que o número de entrevistas ficasse aquém do esperado inicialmente, de modo que foram entrevistados: dois alunos do Ensino Fundamental, sendo um do $8^{\circ}$ ano e o outro do $9^{\circ}$, ambos com deficiência visual congênita (cegueira); um aluno do $2^{\circ}$ ano do Ensino Médio com deficiência visual congênita (visão subnormal); duas professoras da rede pública de ensino do Estado do Rio de Janeiro, sendo uma de Língua Portuguesa com deficiência visual (cegueira) e a outra responsável pelo Núcleo de Apoio Pedagógico (Metropolitana VIII - Niterói-RJ) com visão normal; uma assistente social da Associação Fluminense de Amparo aos Cegos, também, com visão normal.

Mesmo em número reduzido, considera-se que as entrevistas foram enriquecedoras no sentido de ratificar questões apontadas por outros autores, dentre as quais, a que qualifica o sistema escolar como "incapaz de lidar com a deficiência: suas deficiências são bem maiores que as dos assim rotulados 'deficientes'!” (COSTA, 
NEVES, BARONE, 2006, p. 151). Destaca-se, ainda, que a vivência nos contextos escolares visitados foi frutífera, particularmente, por demonstrar que as mudanças no fazer docente em prol da inclusão dos alunos com NEE visuais trará benefícios para a qualidade da educação de todos os alunos, levando-se em conta que, majoritariamente, no que diz respeito à Física, o ensino permanece privilegiando a memorização, o formalismo matemático e a didática baseada na fala e na escrita do professor, associada a uma suposta aprendizagem que depende da audição e da visão por parte dos alunos.

$\mathrm{Na}$ terceira etapa, o GE se dedicou à elaboração de material didáticometodológico, incluindo kits para a abordagem experimental, e à verificação do seu potencial junto a sujeitos com NEE visuais fora do contexto da sala.

Ressalta-se que a produção do material didático tem sido balizada por pressupostos construtivistas, de modo que, a partir de uma problematização que visa contextualizar o conteúdo e despertar o interesse dos alunos para seu estudo, as concepções ou modelos explicativos são explorados como os pontos de partida para a construção dos modelos aceitos cientificamente. A abordagem metodológica predominante caracteriza-se por atividades teórico-práticas, nas quais, o tato, a audição, o trabalho coletivo e o enfoque experimental com o uso de material de baixo custo e de fácil reprodução são privilegiados.

Dentre as atividades teórico-práticas elaboradas pelo GE, foi possível a verificação do potencial daquelas que enfocavam os seguintes conteúdos: movimento retilíneo uniforme (MRU) e uniformemente variado (MRUV), incluindo linguagem gráfica; empuxo; condutores e isolantes elétricos.

As figuras a seguir ilustram o manuseio, por sujeitos com NEE visuais, dos recursos didáticos que integram as atividades.

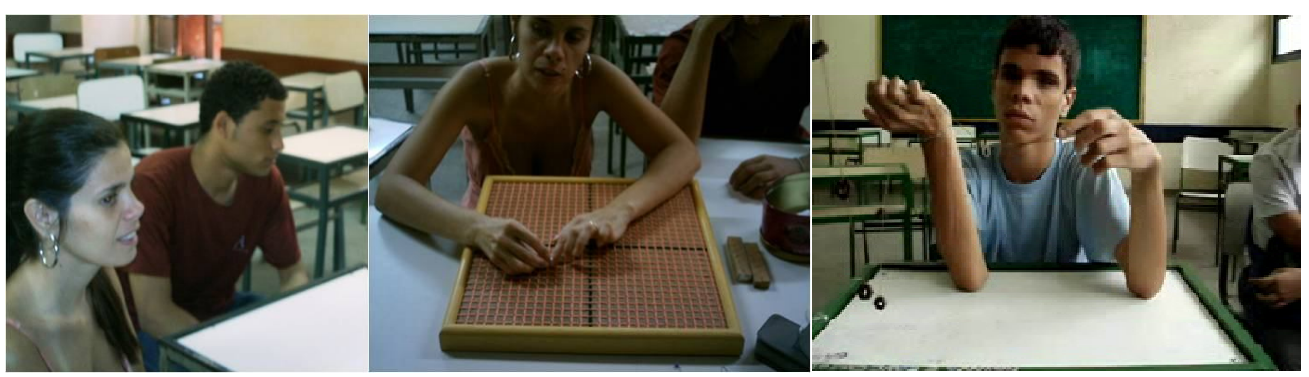

Figura 1: Verificação do potencial do material didático relativo ao conteúdo de MRU, MRUV e linguagem gráfica junto a sujeitos com NEE visuais. 


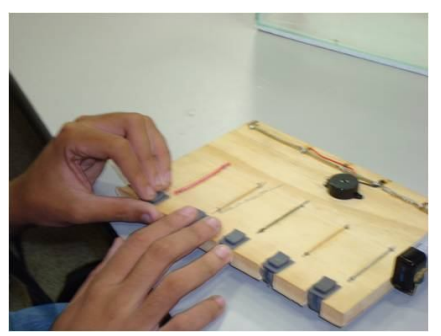

Figura 2: Verificação do potencial do material didático relativo ao conteúdo de condutores e isolantes elétricos por aluno com NEE visuais.

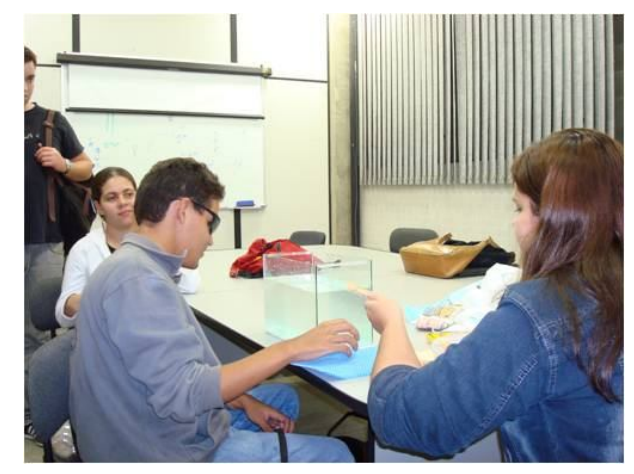

Figura 3: Licenciandos em Física e aluno com NEE visuais, verificando o potencial do material didático sobre empuxo.

Na percepção dos envolvidos na verificação do potencial dos materiais didáticos supra mencionados, os mesmos se caracterizaram como de fácil manuseio e relevantes para a compreensão dos conteúdos, ou seja, no processo de aprendizagem.

Todavia, na concepção do GE, apesar de positivo, esse resultado não validava os produtos decorrentes de suas atividades na perspectiva de um ensino de Física inclusivo em classes comuns de escolas da rede regular. Sendo assim, paralelamente à produção de novos materiais, componentes do GE retornaram à escola que se mostrou receptiva ao seu trabalho, com o intuito de sondar as possibilidades de ser aplicada uma atividade teórico-prática sobre o tema Som e Audição em uma turma do $9^{\circ}$ ano do Ensino Fundamental que possuía um aluno com NEE visuais. A proposta foi prontamente aceita pela direção e pelo professor de Ciências da turma, tendo sido disponibilizada ao GE 4 horas/aula para o desenvolvimento da atividade.

Os critérios adotados pelo GE para considerar a validade da proposta de ensino na perspectiva da inclusão foram: nível de receptividade e envolvimento dos alunos (videntes e não vidente) no desenvolvimento das atividades planejadas; nível de entrosamento entre os videntes e o não vidente na realização das atividades; pertinência 
do material didático (texto impresso e experimentos) elaborado para o desenvolvimento do conteúdo; evolução conceitual dos alunos.

Em relação aos dois primeiros critérios, considera-se que os resultados alcançados foram excelentes. A figura 4 ilustra momentos do desenvolvimento da proposta e, de certo modo, ratifica a análise do GE.

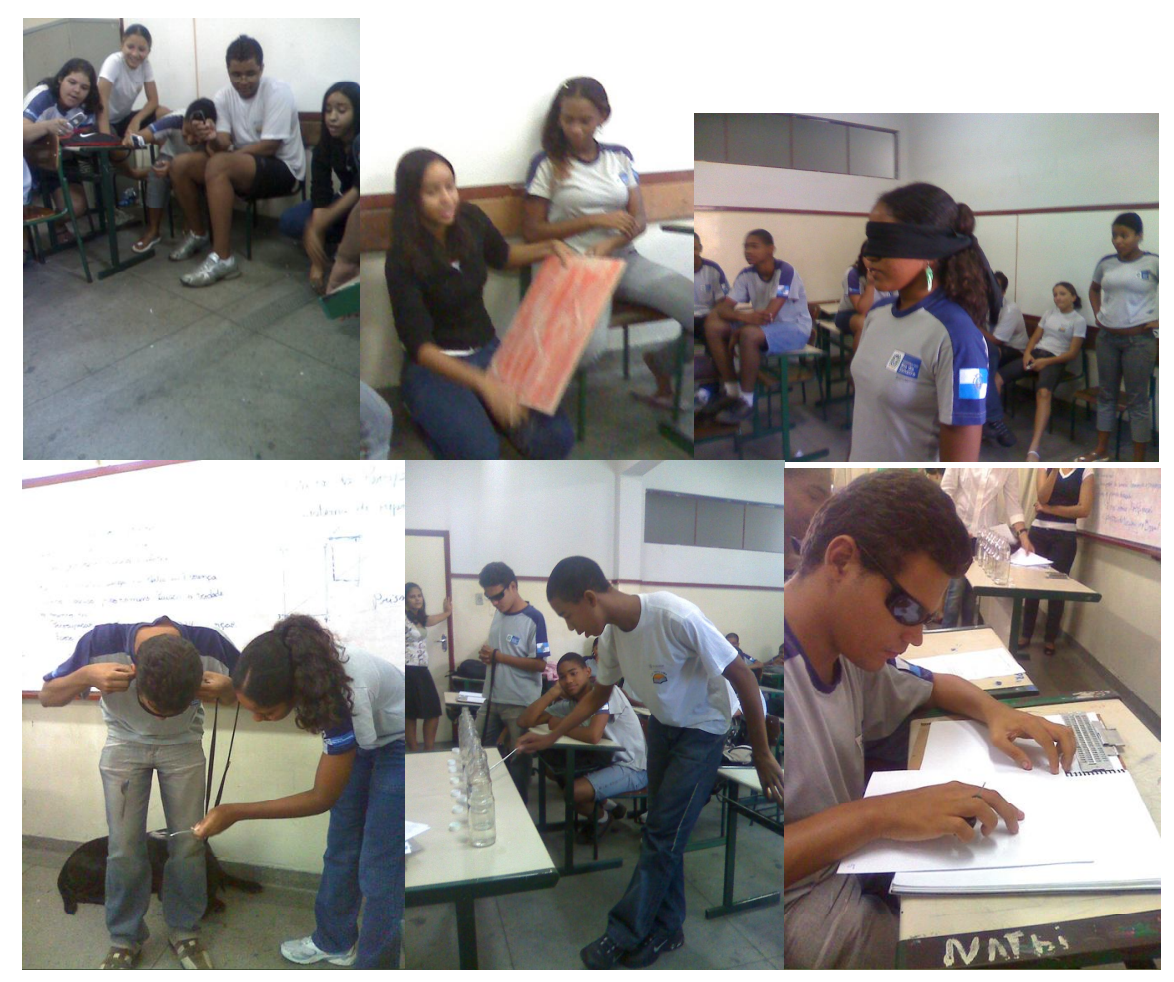

Figura 4: Momentos de aplicação da proposta de ensino Som e Audição em uma turma de $9^{\circ}$ ano do Ensino Fundamental.

No que se refere ao material didático, avalia-se que os experimentos contribuíram sobremaneira para a participação dos alunos, tendo sido considerado pelo GE como fator preponderante na efetivação de diálogos entre os alunos e entre o professor e a turma. Sobre o texto, cabe destacar que a adoção de sua impressão em Braille, para o aluno não vidente, foi de suma importância para a autonomia do mesmo nas discussões em classe e no processo de (re)construção do conhecimento.

A comparação entre as respostas dos alunos a perguntas instigadoras no início do processo de ensino e as fornecidas no processo de avaliação ao término da atividade indica que houve evolução conceitual, entretanto, em um nível aquém do esperado. $\mathrm{Na}$ avaliação do GE, um dos fatores que influenciou esse resultado foi o tempo destinado 
ao desenvolvimento da proposta (4h/aula). Essa carga horária limitou as discussões, mediadas pelo professor, que objetivavam facilitar o processo de aprendizagem e, consequentemente, a evolução conceitual dos alunos.

Os resultados alcançados pelo GE, ao longo das etapas descritas, permitem reafirmar as análises de outros autores, dentre eles Camargo (2008), no sentido de que a principal barreira à inclusão reside nas dificuldades dos professores em planejar e executar propostas de ensino que se contraponham à abordagem tradicional centrada no discurso do professor e que pressupõe a passividade dos alunos.

Desse modo, as mudanças mais significativas que se espera na ação docente não são específicas para a inclusão dos alunos com NEE visuais. A extensa bibliografia sobre a formação de professores de Física já tem apontado que as mesmas são necessárias para que o ensino de Física, no contexto escolar, se revista de significado para os alunos.

Ciente de que essa iniciativa não era suficiente para gerar mudanças significativas na Licenciatura em Física da UFF, o GE, a partir da avaliação de seus produtos por sujeitos com NEE visuais e pelos resultados alcançados no processo de ensino na classe comum da rede regular, passou a difundir o conhecimento conquistado nas disciplinas Produção de Material Didático e Estratégias para o Ensino de Física I e II, obrigatórias no currículo do referido Curso.

\section{Considerações Finais}

A repercussão das atividades do GE, no âmbito do Instituto de Física, se destaca como principal resultado, pois tem servido para derrubar tabus e gerar perspectivas curriculares na Licenciatura em Física da UFF.

Desse modo, o GE ratifica as análises de Sanches e Teodoro (2007), no sentido de que as iniciativas daqueles formadores que visam contribuir para a melhoria da formação de futuros professores, na perspectiva da educação inclusiva, deva se iniciar com as condições que o contexto educacional oferece.

Além disso, o GE pode perceber que a inserção de disciplinas obrigatórias voltadas para a educação inclusiva nos Cursos de Licenciatura não será suficiente para a formação de professores aptos ao planejamento e desenvolvimento de um ensino de qualidade para todos. Pelo contrário, considera que a qualidade esperada e que 
permitirá, na prática, a inclusão, está condicionada a ações que favoreçam ao futuro professor: refletir sobre o fazer docente, exercitar sua criatividade na elaboração de planejamentos de ensino alternativos ao rotulado como tradicional e saber reconhecer sua responsabilidade no fracasso e evasão dos alunos da escola.

\section{Referências bibliográficas}

ALMEIDA, Lucia da Cruz de et al. Videntes e não-videntes: subsídios para um ensino inclusivo. In: XVIII Simpósio Nacional de Ensino de Física. Vitória: UFES/SBF, 2009. Disponível em: <http://www.sbf1.sbfisica.org.br/eventos/snef/xviii/sys/resumos/T00651.pdf $>$. Acesso em: 15 maio 2009.

BRASIL. Constituição da República Federativa do Brasil, 1988. Disponível em: <http://www.senado.gov.br/SF/legislacao/const/>. Acesso em: 10 abril 2007.

. Decreto $N^{o} 3298$ de 20 de dezembro de 1999, 1999. Disponível em: <http://www.planalto.gov.br/ccivil_03/decreto/D3298.htm>. Acesso em: 30 agosto 2007.

Lei de Diretrizes e Bases da Educação Nacional. 1996. Disponível em: <http://www.planalto.gov.br/ccivil_03/Leis/L9394.htm>. Acesso em: 20 abril 2007.

Resolução CNE/CEB No 2, de 11 de setembro de 2001. Disponível em: <http://portal. mec.gov.br/cne/arquivospdf/CEB0201.pdf>. Acesso em: 01 dezembro 2009.

MEC. Portaria No 1793 de dezembro de 1994. Disponível em: <http://portal.mec.gov.br/seesp/arquivos/pdf/port1793.pdf>. Acesso em: 30 agosto 2007.

— MEC - SEESP. Política Nacional de Educação Especial na Perspectiva da Educação Inclusiva. s/da. Disponível em: <http://portal.mec.gov.br/seesp/arquivos/pdf/politica.pdf>. Acesso em: 20 julho 2009.

em:

, MEC. Política de educação inclusiva - direito à diversidade. s/db. Disponível $<$ http://portal.mec.gov.br/index.php?option=com_content\&view=article \&id=12345\&ati vo=711\&Itemid=709>. Acesso em: 15 dezembro 2009 .

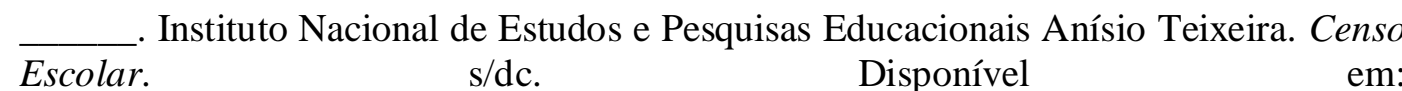
<http://www.inep.gov.br/basica/censo/Escolar/questionarios>. Acesso em: 31 julho 2007.

COSTA, Isa; MARINHO, Karla Silene Oliveira; ALMEIDA, Lucia da Cruz de. O ensino de Física no processo de inclusão de alunos com NEE visuais. In: 
FERNANDES, Neiva Santos Masson; DOMINICK, Rejany; CAMARGO, Sueli (orgs.). Formação de professores - projetos, experiências e diálogos em construção. Niterói RJ: EdUFF, 2008, p. 41-53.

CAMARGO, Éder Pires de. Ensino de Física e deficiência visual: dez anos de investigação no Brasil. São Paulo: Plêiade/FAPESP, 2008.

COSTA, Luciano Gonsalves; NEVES, Marcos César Danhoni; BARONE, Dante Augusto Couto. $\mathrm{O}$ ensino de Física para deficientes visuais a partir de uma perspectiva fenomenológica. Ciência e Educação, São Paulo: UNESP, v.12, n. 2, p. 143-153, agosto, 2006. Disponível em <http://www2.fc.unesp.br/cienciaeeducação. Acesso em: 15 março 2007.

DUK, Cynthia. Educar na diversidade: material de formação docente. 3. ed., Brasília: [MEC, SEESP], 2006. 266 p. Disponível em: <http://portal.mec.gov.br/seesp/arquivos/pdf/educarnadiversidade2006.pdf.> Acesso em: 23 julho 2009.

GUIJARRO, Maria Rosa Blanco. Inclusão: um desafio para os sistemas educacionais. Ensaios Pedagógicos - construindo escolas inclusivas, Brasília: MEC, SEESP, 2005, p. 7-14. Disponível em: $<$ http://portal.mec.gov.br/seesp/index.php?option=content\&task=view\&id=147\&Itemid =299>. Acesso em: 30 maio 2007.

MANTOAN, Maria Teresa Eglér. Inclusão é o privilégio de conviver com as diferenças. Nova Escola On-line. Edição 182, maio, 2005.

Ensinando a turma toda: as diferenças na escola. In:

diferenças na escola. Petrópolis, RJ: Vozes, 2008, p. 59 - 67. (Org.). O desafio das

PLETSCH, Márcia Denise. A formação de professores para a educação inclusiva: legislação, diretrizes políticas e resultados de pesquisas. Educar, Curitiba, n. 33, p. 143 - 156, 2009.

RODRIGUES, David. Desenvolver a Educação Inclusiva: dimensões do desenvolvimento profissional. Inclusão: Revista da Educação Especial, Brasília, v. 4, n 2, p. 7-16, jul./out. 2008.

SANCHES, Isabel; TEODORO, António. Procurando indicadores de educação inclusiva: as práticas dos professores de apoio educativo. Revista Portuguesa de Educação, 2007, 20(2), p. 105 -149. Universidade do Minho. 
SANTOS, Luciana Tavares dos. O olhar do deficiente visual para o ensino de Física. In: VII Encontro de Pesquisa em Ensino de Física. Anais... São Paulo: SBF, 2000, CDROM.

SOUZA, Salete de; LEBEDEF, Tatiana Bolívar; BARLETTE, Vânia Elizabeth. Percepções de jovens e adultos surdos acerca de suas vivências escolares. In: XVII Simpósio Nacional de Ensino de Física, 2007, São Luis. Disponível em: $<$ http://www.sbf1.sbfisica.org.br/eventos/snef/xvii/programa/lista_trabalho.asp?sesId=5 7\&sesPerDescricao=Pain\%E9is8>. Acesso em: 29 mar. 2007.

VERÍSSIMO, Hildemar. Inclusão: a educação da pessoa com necessidades educacionais especiais - velhos e novos paradigmas. Revista Benjamin Constant, 18 ed, abril, 2001. Disponível em: <http: //www.ibc.gov.br>. Acesso em: 24 julho, 2007. 